\title{
Erratum to: Improved Mechanical Properties of Various Fabric- Reinforced Geocomposite at Elevated Temperature
}

\author{
SNEHA SAMAL, ${ }^{1,3,4}$ NHAN PHAN THANH,,${ }^{1,2}$ IVA PETRÍKOVÁ, ${ }^{1}$ and \\ BOHDANA MARVALOVÁ ${ }^{1}$ \\ 1.-Department of Mechanics, Technical University of Liberec, 46117 Liberec 1, Czech Republic. \\ 2.-Present address: Department of Mechanics \& Materials, Nha Trang University, 02 Nguyen \\ Dinh Chieu, Nha Trang, Khanh Hoa, Vietnam. 3.—e-mail: samasneha@gmail.com. 4.—e-mail: \\ Sneha.Manjaree.Samal@tul.cz
}

\section{ERRATUM TO: JOM}

DOI 10.1007/S11837-015-1420-X

Bohdana Marvalová was misspelled in the article. It appears correctly here.

The online version of the original article can be found under doi:10.1007/ s11837-015-1420-x. 